\title{
A Business Perspective on Internet of Things
}

\author{
Arbana Kadriu \\ SEE University, Macedonia \\ Nusret Haliti \\ SEEU Technological Park
}

\section{Abstract}

Sensors are rapidly being integrated everywhere, in every aspect of our lives, ranging from home automation to wearable sensors for pervasive healthcare management. We hear ubiquitously for ubiquitous devices. In recent years, increasingly we are listening and talking about phrases like "Internet of Things", "M2M", "Context awareness", "Web of Things", which announce the new era to come, where we will be surrounded with smart devices, which communicate with each other to easer and beautify our lives. This article reports on our findings about the business perspective on internet of things. It involves literature review on the internet of things world and its impact in the business domain.

Keywords: internet of things, sensor data, mobile environment, sensor applications JEL classification: $030,031,033, \mathrm{M} 13$

\section{Introduction}

In today's world of wireless telecommunications, Internet of Things (IOT) are evolving exponentially (Atzori et al., 2010). The core idea of loT paradigm is that different things in our everyday life will be capable to identify themselves, sense the environment, interact with other things around them and even process data before communicating with other another objects and data centres over the Internet targeting to achieve particular beneficial purpose. Critical hardware infrastructure used to build IOT includes: RFID, NFC and Sensor Networks (Whitmore et al., 2014). Most of the sensors utilized until now are wireless, among which employed to "build wireless sensor networks are: wireless personal area network (WPAN) (e.g.Blvetooth), wireless local area network (WLAN) (e.g. Wi-Fi), wireless metropolitan area network (WMAN) (e.g. WiMAX), wireless wide area network (WWAN) (e.g. $2 G$ and $3 G$ networks), and satellite network (e.g. GPS). Sensor networks also use two types of protocols for communication: non-IP based (e.g: Zigbee and Sensor-Net) and IPbased protocols (NanoStack, PhyNet, and IPv6)" (Perera et al., 2013). Wireless Sensor Networks (WSNs) are defined as in self-organizing wireless networks aimed to observe physical measurements, to pass their values through the network to a main station where these values can be kept and processed further (Matin et al., 2012; Guy, 2006; Lewis, 2004; Stankovic, 2008; Townsend et al., 2005; Akyildiz et al., 2002). The notion sensor web is introduced which is related to the idea of connection of all the sensors, together their data together aiming to share common objectives (Botts et al., 2007). There are different sensor web systems, and most of these systems are dedicated to one type of application only (Mercury dedicated for Parkinson monitoring, CenceMe is dedicated for social network communication etc.) (Al Nuaimi et al., 2012). To develop an effective IOT environment, there are incorporated standards to follow aspiring enable real time integration of heterogeneous sensors (ISO/IEC JTC 1/SC 6; IOT-GSI; JCA IOT and SC\&C; JCA-IOT). Despite the transport of the sensor data to a 
central location, there can be also a flow of data in reverse direction - from the sink to the sensor (Su et al., 2006).

All sensor records can lead to unlimited possibilities of applications and business models, such as telematics, smart metering (electricity, gas, water, air/pollution etc.), automotive (car diagnostics, remote command execution etc.), home automation and so on.

\section{Automotive Telematics}

Telematics can be described "as the information-intensive applications that are being enabled for vehicles by a mixture of telecommunications and information technology" (Duri et al., 2002). Companies are developing smart console operating systems, which gather data from cars' embedded sensors, delivering in this way instantaneous critical information, enabling in this way security, connectivity and suitability services to third-party applications and drivers, as well (Rong et al., 2015).

Regarding to (Lenfle et al., 2003), automotive telematics is categorized in four main categories:

1. safety and security - instant signalling of SOS need from the car's side when accidents happen, and remote maintenance from the service side.

2. information and navigation - navigation maps and, together with assistance for points of interest as nearby restaurants, pharmacies etc.

3. communication: phone conversations, e-mails, videoconferencing etc.

4. entertainment - online shopping, games for passengers etc.

The first category implies new business models regarding the

1. insurance (pay-for-use) - clients choose from a collections of discretion policies, where data are collected from telematics service provider side, estimating the client's bill [ (Duri et al., 2002; Desyllas et al., 2012),

2. car sharing - a method that is used used to verify safe arrival of participants at predefined meeting locations (Raney, 2006),

3. data protection and data sharing - building frameworks that enable data collections prior to sending these data to service providers (Duri et al., 2004).

The second category has to do with information and navigation, which infers patterning, service location, data handling and risk estimation in telematics networks (Neumann, 2017), as well as findings news ways in vehicle tracking when there is no information about a geo location (Haliti et al., 2017).

Communication involves development of new platforms and businesses regarding the Integration of web 2.0 in the new car models (Gil-Castineira et al., 2009), WLAN hot spot services delivered to vehicles around gas stations (Pau et al., 2003), new methods for obtaining an internet connection (Crocker et al., 2008), bi-directional communication between a vehicle and a vehicle key (Desai et al., 2008), prevention from using a handheld wireless communication device without a hands-free communication device when the vehicle is in motion (Nath et al., 2010), vehicle-tovehicle communication system (Bellur et al., 2014) etc.

According to a study described in (Living, 2012), 90 per cent of the new cars sold worldwide by 2025, will come with embedded telematics, creating a value chain of INR1,343 billion euros, which will bring to new business models regarding the entertainment category.

\section{Smart metering and monitoring}

Smart metering and monitoring infrastructure indicates to methods that measure and monitor remotely energy usage from devices such as electricity, gas, and water 
metrics, as well as environmental metering and monitoring (Khan et al., 2012). Smart meters will have to be installed for millions of households and companies and get connected to transaction platforms (Haller et al., 2008). Smart metering brings to new approaches for energy management in smart factories (Shrouf et al., 2014), spot areas of potential improvement, or predict future outcomes and optimize operations, leading to lower costs and higher productivity (Lee et al., 2015), as well as shift from infrastructure to data-driven ecosystem (Vermesan et al., 2013; Simmhan et al., 2013; Stimmel, 2016), which produces new business intelligence applications, and business big data analytics (Lee et al., 2015).

\section{Home automation}

For this category, we presume a home network created by a number of home automation systems (e.g., healthcare systems, smart appliances and security systems) for continuous real-time monitoring of residents, the home environment, and the nearby community environment (Li et al., 2011). Typically for this network, as the backbone is used WiFi, which enables higher bandwidth data transfer as well as higher sampling rates (Gubbi et al., 2013). The main purpose of such system is the property protection and home energy savings, by allowing users to adjust the lights, control the climate, manage the security system, receive automatic event notifications, lock/unlock doors etc. (Lee et al., 2015). This implies that home automation systems move towards the energy business (Palensky et al., 2011). Experiments show that such monitoring systems can reduce the energy consumption for lighting loads by 40\% (Park et al., 2009). Furthermore, home automation systems track and save human actions, try to forecast their actions time ahead, organizing all things around them one step ahead aiming to fit their demands/preferences and providing them the accessibility, productivity, and wellbeing (Li et al., 2011). As an extension to the home automation, is the healthcare home monitoring systems, which enable doctors' fast medical prognosis and diagnosis, improving in this way disease treatment with lower medical costs for aged-people and people with disabilities (Luo et al., 2010; Domingo, 2012).

\section{Conclusion}

In this paper we have described the main applications of internet of things, such as automotive telematics, smart metering and home automation, associated by the analysing the research done for these categories. All these new aspects of IOT applications require new business models and deliveries that will ensure sustainable and appropriate possibilities to the new era that is coming.

\section{References}

1. Akyildiz, I. F., Su, W., Sankarasubramaniam, Y., Cayirci, E. (2002), "Wireless sensor networks: a survey", Computer Networks, Vol. 38, No. 4, pp. 393-422.

2. Al Nuaimi, K., Al Nuaimi, M., Mohamed, N., Jawhar, I., Shuaib, K. (2012), "Web-based wireless sensor networks: a survey of architectures and applications", in proceedings of the 6th International Conference on Ubiquitous Information Management and Communication, Article No. 113. Kuala Lumpur, Malaysia, 20-22 February 2012.

3. Atzori, L., lera, A., Morabito, G. (2010), "The Internet of Things: A survey", Computer Networks, Vol. 54, No. 15, pp. 2787-2805.

4. Bellur, B. R., Bhattacharya, D., Iyer, A. V. (2014), "Threat mitigation in a vehicle-tovehicle communication network", U.S. Patent No. 8,819,414, U.S. Patent and Trademark Office, Washington, DC. 
5. Botts, M., Robin, A. (2007), "Bringing the sensor web together", Geosciences, Vol. 6, pp. 46-53.

6. Crocker, D. A., Gryc, A. J., Glaza, M. J., Correia, J. J. (2008), "Establishing mobile terminated connections with dynamically assigned wireless IP terminals in automotive telematics applications", U.S. Patent No. 7,336,943, U.S. Patent and Trademark Office Washington, DC.

7. Desai, T. B., Drescher, S. A., Wallace, M. D. (2008), "Vehicle key for bi-directional communication with vehicle", U.S. Patent Application No. 12/042,358.

8. Desyllas, P., Sako, M. (2013), "Profiting from business model innovation: Evidence from Pay-As-You-Drive auto insurance", Research Policy, Vol. 42, No. 1, pp. 101-116.

9. Domingo, M. C. (2012), "An overview of the Internet of Things for people with disabilities", Journal of Network and Computer Applications, Vol. 35, No. 2, pp. 584596.

10. Duri, S., Elliott, J., Gruteser, M., Liu, X., Moskowitz, P., Perez, R., Singh, M., Tang, J. M. (2004), "Data protection and data sharing in telematics", Mobile networks and applications, Vol. 9, No. 6, pp. 693-701.

11. Duri, S., Gruteser, M., Liu, X., Moskowitz, P., Perez, R., Singh, M., Tang, J. M. (2002), "Framework for security and privacy in automotive telematics", in proceedings of the 2nd international workshop on Mobile commerce, 28 September 2002, Atlanta, GA. ACM, pp. 25-32.

12. Gil-Castineira, F., Chaves-Dieguez, D., Gonzalez-Castano, J., Costa-Montenegro, E. (2009), "Integration of web 2.0 with automotive user interfaces via nomadic devices", in proceedings of the 2009 Digest of Technical Papers International Conference on Consumer Electronics, 10-14 January 2009, Las Vegas, NV, IEEE, pp. 1-2.

13. Gubbi, J., Buyya, R., Marusic, S., \& Palaniswami, M. (2013). Internet of Things (IoT): A vision, architectural elements, and future directions. Future generation computer systems, $29(7), 1645-1660$.

14. Guy, C. (2006), "Wireless sensor networks", in proceedings of the Sixth International Symposium on Instrumentation and Control Technology: Signal Analysis, Measurement Theory, Photo-Electronic Technology, and Artificial Intelligence, International Society for Optics and Photonics, Beijing, China.

15. Haliti, N., Kadriu, A., \& Jusufi, M. (2017). An approach for speed limit determination for vehicle tracking in case of GID ambiguity and lack of information in navigation maps. International Journal of Pervasive Computing and Communications, Vol. 13, No. 3, pp. 252-263.

16. Haller, S., Karnouskos, S., Schroth, C. (2008), "The internet of things in an enterprise context", in Domingue J., Fensel D., Traverso P. (Eds,), Future Internet Symposium - FIS 2008, Lecture Notes in Computer Science, Vol. 5468, Springer, Berlin, Heidelberg, pp. $14-28$.

17. Internet of Things Global Standards Initiative (IOT-GSI), available at: http://www.itu.int/en/ITU-T/gsi/iot/Pages/default.aspx (13 August 2018)

18. Joint Coordination Activity on Internet of Things and Smart Cities and Communities (JCA IOT and SC\&C), available at: https://www.itu.int/en/ITU-T/jca/iot/Documents/ToR/Scope-and-ToR-JCA-IOT-SC-C18112015.pdf (13 August 2018)

19. Joint Coordination Activity on Internet of Things (JCA-IOT), available at: http://www.geneve-int.ch/joint-coordination-activity-internet-things-jca-iot (13 August 2018)

20. Khan, R., Khan, S. U., Zaheer, R., Khan, S. (2012), "Future internet: the internet of things architecture, possible applications and key challenges", in the proceedings of the 10th International Conference on Frontiers of Information Technology (FIT), 17-19 December 2012, Islamabad, India, IEEE, pp. 257-260.

21. Lee, I., Lee, K. (2015), "The Internet of Things (IOT): Applications, investments, and challenges for enterprises", Business Horizons, Vol. 58, No. 4, pp. 431-440. 
22. Lenfle, S., Midler, C. (2003), "Innovation in automotive telematics services: characteristics of the field and management principles", International journal of automotive technology and management, Vol. 3, No. 1-2, pp. 144-159.

23. Lewis, F. L. (2004) "Wireless Sensor Networks", in Cook, D., \& Das, S. K. (Eds.), Smart Environments: Technologies, Protocols, and Applications, Vol. 34, John Wiley \& Sons, Inc., Hoboken, NJ, USA. pp. 13-46.

24. Li, X., Lu, R., Liang, X., Shen, X., Chen, J., Lin, X. (2011), "Smart community: an internet of things application", IEEE Communications Magazine, Vol. 49, No. 11, pp. 68-75.

25. Living, G. C. (2012), 2025 Every Car Connected: Forecasting the Growth and Opportunity, GSMA, White paper. Available at: https://www.gsma.com/iot/wpcontent/uploads/2012/03/gsma2025everycarconnected.pdf / 15th August, 2018.

26. Luo, H., Ci, S., Wu, D., Stergiou, N., Siu, K. C. (2010), "A remote markerless human gait tracking for e-healthcare based on content-aware wireless multimedia communications", IEEE Wireless Communications, Vol. 17, No. 1, pp. 44-50.

27. Matin, M. A., Islam M. M. (2012), Overview of Wireless Sensor Network, in Matin, M. A. (Ed.), Wireless Sensor Networks - Technology and Protocols, Intech. pp. 3-24.

28. Nath, S., Patel, R. (2010), "Method for automobile safe wireless communication", U.S. Patent No. 7,738,831, U.S. Patent and Trademark Office, Washington, DC.

29. Neumann, T. (2017), "Automotive and telematics transportation systems", in proceedings of 2017 International Siberian Conference on Control and Communications (SIBCON), 29-30 June 2017, Astana, Kazakhstan, IEEE, pp. 1-4.

30. Palensky, P., Dietrich, D. (2011), "Demand side management: Demand response, intelligent energy systems, and smart loads", IEEE transactions on industrial informatics, Vol. 7, No. 3, pp. 381-388.

31. Park, T. J., Hong, S. H. (2009), "Experimental case study of a BACnet-based lighting control system", IEEE transactions on automation science and engineering, Vol. 6, No. 2, pp. 322-333.

32. Pau, L-F, Oremus, M. H. P., (2003), "Wlan Hot Spot Services for the Automotive and Oil Industries: a Business Analysis " (28 2003 4,). ERIM Report Series Reference No. ERS-2003039-LIS. Available at SSRN: https://ssrn.com/abstract=411659

33. Perera, C., Zaslavsky, A., Christen, P., Georgakopoulos, D. (2013), "Context Aware Computing for The Internet of Things: A Survey," IEEE Communications Surveys \& Tutorials, Vol. 16, No. 1, pp. 414-454.

34. Raney, S. (2006), "Method for GPS carpool rendezvous tracking and personal safety verification", U.S. Patent No. 7,136,747, U.S. Patent and Trademark Office. Washington, DC.

35. Rong, K., Hu, G., Lin, Y., Shi, Y., Guo, L. (2015), "Understanding business ecosystem using a 6C framework in Internet-of-Things-based sectors", International Journal of Production Economics, Vol. 159, pp. 41-55.

36. Shrouf, F., Ordieres, J., Miragliotta, G. (2014), "Smart factories in Industry 4.0: A review of the concept and of energy management approached in production based on the Internet of Things paradigm", in proceedings of 2014 IEEE International Conference on Industrial Engineering and Engineering Management (IEEM), 9-12 December 2014, Bandar Sunway, Malaysia, IEEE, pp. 697-701.

37. Simmhan, Y., Aman, S., Kumbhare, A., Liu, R., Stevens, S., Zhou, Q., Prasanna, V. (2013), "Cloud-based software platform for big data analytics in smart grids", Computing in Science \& Engineering, Vol. 15, No. 4, pp. 38-47.

38. Stankovic, J. A. (2008), "Wireless Sensor Networks", Computer, Vol. 41, No. 10, pp. $92-$ 95.

39. Stimmel, C. L. (2016), Big data analytics strategies for the smart grid, CRC Press, Boca Raton, FL.

40. Su, W., Akan, O. B., Cayirci, E. (2006), "Communication Protocols for Sensor Networks", in Raghavendra, C. S., Sivalingam, K. M., Znati, T. (Eds.), Wireless Sensor Networks, Springer, pp. 21-50.

41. Telecommunications and information exchange between systems (ISO/IEC JTC 1/SC 6), available at: https://www.iso.org/committee/45072.html (13 August 2018) 
42. Townsend, C., Steven Arms (2005), "Wireless Sensor Networks: Principles and Applications. Sensors, Transducers and Detectors", in Wilson, J. S. (Ed.), Sensor Technology Handbook, Elsevier.

43. Vermesan, O., Friess, P. (2013), Internet of things: converging technologies for smart environments and integrated ecosystems, River Publishers, Aalborg, Denmark.

44. Whitmore, A., Agarwal, A., Da XU, L. (2014), "The Internet of Things-A survey of topics and trends", Information Systems Frontiers, Vol. 17, No. 2, pp. 261-274.

\section{About the authors}

Arbana Kadriu holds a PhD degree in Computer Sciences from Ss. Cyril and Methodius University in Skopje from 2008, with focus on natural language processing and information retrieval. She is associate professor at the Faculty of Contemporary Sciences and Technologies at SEE University in Macedonia. She has also background in artificial intelligence, machine learning, programming paradigms, software engineering and e-learning. Also, she is mentoring several master thesis that involve the web information retrieval and e-learning. She is author of more than 30 research papers. The author can be contacted at a.kadriu@seeu.edu.mk.

Nusret Haliti holds a MSc degree in Telecommunications and Embedded Microcomputers Engineering from Ss. Cyril and Methodius University in Skopje from 2010. He is CEO and Founder of Bridge-Technology, which is a company that develops vehicle tracking applications and business models, facilitating the IOT infrastructure. His main interest and expertise are in the field of embedded computing, machine to machine communication, internet of things, communication networks etc. The author can be contacted at nusret.haliti@bridge-technology.net. 